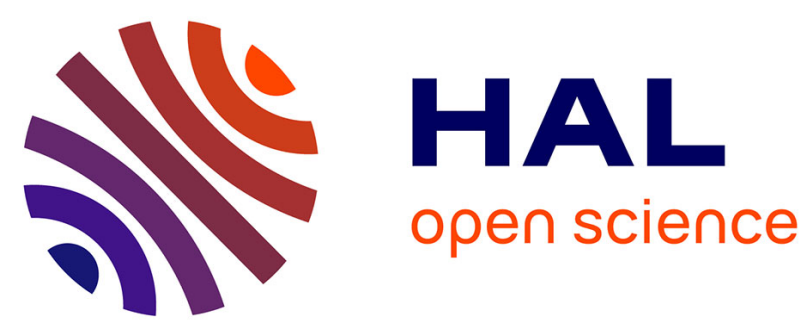

\title{
Tuning the morphology of Te one-dimensional nanostructures by template-free electrochemical deposition in an ionic liquid
}

Laura Thiebaud, Sophie Legeai, Nicolas Stein

\section{To cite this version:}

Laura Thiebaud, Sophie Legeai, Nicolas Stein. Tuning the morphology of Te one-dimensional nanostructures by template-free electrochemical deposition in an ionic liquid. Electrochimica Acta, 2016, 197, pp.300 - 306. 10.1016/j.electacta.2015.12.084 . hal-01494529

\section{HAL Id: hal-01494529 \\ https://hal.univ-lorraine.fr/hal-01494529}

Submitted on 4 Oct 2021

HAL is a multi-disciplinary open access archive for the deposit and dissemination of scientific research documents, whether they are published or not. The documents may come from teaching and research institutions in France or abroad, or from public or private research centers.
L'archive ouverte pluridisciplinaire HAL, est destinée au dépôt et à la diffusion de documents scientifiques de niveau recherche, publiés ou non, émanant des établissements d'enseignement et de recherche français ou étrangers, des laboratoires publics ou privés.

\section{(1) (1) $\$$}

Distributed under a Creative Commons Attribution - NonCommercial - NoDerivatives 44.0 


\section{Tuning the morphology of Te one-dimensional nanostructures by template-free electrochemical deposition in an ionic liquid}

Laura Thiebaud, Sophie Legeai*, Nicolas Stein

Institut Jean Lamour, UMR CNRS 7198, University of Lorraine, 1 boulevard Arago, 57078

Metz Cedex 3, France

* Corresponding author: sophie.legeai@univ-lorraine.fr Tel.: +33 387315463.

E-mail addresses: laura.thiebaud@univ-lorraine.fr (L. Thiebaud), $\underline{\text { sophie.legeai@ univ- }}$

lorraine.fr (S. Legeai), nicolas.stein@univ-lorraine.fr (N.Stein).

${ }^{1}$ ISE Member.

Abstract

Template-free electrodeposition of Te one-dimensional (1 D) nanostructures was carried out from an ionic liquid binary mixture: 1-ethyl-1-octyl-piperidinium

bis(trifluoromethylsulfonyl)imide:1-ethyl-1-octyl-piperidinium bromide

(EOPipTFSI:EOPipBr 95:5 (mol\%)). SAED and XRD analyses confirm the formation of Te

1D nanostructures with a hexagonal single crystalline structure following the [001] direction.

A systematic study of the influence of synthesis parameters on the deposits morphology has

shown that it is possible to control the shape and the dimensions of the deposited

nanostructures. Specifically, the applied potential has a strong influence on the morphology of

the deposits. Nanowires or hollow nanostructures can be obtained, depending on mass

transport conditions, as confirmed by the use of a soluble anode.

Keywords: Electrodeposition, Nanowires, Tellurium, Ionic liquid, Hollow nanostructures

1. Introduction

Tellurium (Te) and its binary or ternary compounds are used in many domains such as piezoelectric devices [1], gas sensors [2], photoconductors [3], solar cells [4] and thermoelectric generators and coolers [5]. Thermoelectricity, which consists in a reversible 
conversion of heat into electricity and conversely, allows the harvesting of wasted heat and therefore is particularly interesting for the improvement of energy systems efficiency [6]. The thermoelectric performances are evaluated by the figure of merit ZT given by the equation 1: Equation $1 \mathrm{ZT}=\frac{\mathrm{S}^{2} \sigma}{\mathrm{K}_{\mathrm{e}}+\mathrm{K}_{\mathrm{g}}} \mathrm{T}$

where $\mathrm{S}$ is the Seebeck coefficient, $\sigma$ is the electrical conductivity, $\mathrm{K}_{\mathrm{e}}$ is the electronic thermal conductivity, $\mathrm{K}_{\mathrm{g}}$ is the phonon thermal conductivity and $\mathrm{T}$ is the temperature.

The performances of thermoelectric compounds can be improved by nanostructuring [6-9]. Among nanostructures, one-dimensional nanostructures like nanowires [10-13] and core-shell nanowires [13-17] are particularly promising due to the high phonon interface scattering and the blocking of the phonon conduction along the wire axis which lead to an increase of the thermoelectric conversion efficiency. Te nanowires can represent a base to create core-shell structures, being the core that could be further capped with a shell to get arrays of Te-based thermoelectric nanostructures like BiTe [17-20], AgTe [20-22] or LaTe [23]. Various approaches have been developed to synthesize Te nanowires, such as physical and chemical vapor deposition [24,25], hydrothermal process [26-28], galvanic displacement reaction [29-31] or electrochemical deposition (ECD) [32-36]. Arrays of Te 1D nanostructures have already been obtained by ECD, mainly by template-assisted electrodeposition, using anodic aluminium oxide (AAO) [33] or polycarbonate etched membranes templates [34]. However, template-assisted methods involve multiple fabrication steps, like the preparation of the template and its removing which is necessary for the further deposition of a thin upper layer leading to core-shell structures. A single step template-free synthesis route would be more convenient and easier to perform. Room-Temperature Ionic Liquids (RTILs) are promising solvents for template-free synthesis as they can act as capping agents leading to the synthesis of nanostructures. As example, Ma et al. synthesized Te nanowires via a chemical route using triethanolamine tetrafluoroborate ionic liquid as an 
additive in an aqueous solution [37]. Additionally RTILs present specific advantages for ECD purposes such as a wide electrochemical window, a good electrical conductivity and a high thermal stability which gives access to highly crystalline materials. Template-free electrodeposition of 1D nanostructures in RTILs is little present in the literature. Steichen and Dale showed that selenium nanorods can be grown in an imidazolium-based ionic liquid mixture: 1-ethyl-3-methylimidazolium tetrafluoroborate/chloride $\left[\mathrm{C}_{2} \mathrm{mIm}\right]\left[\mathrm{BF}_{4}\right] /\left[\mathrm{C}_{2} \mathrm{mIm}\right] \mathrm{Cl}$ [38]. Al nanowires were obtained by $\mathrm{Su}$ et al. in a Lewis acidicionic liquid $\mathrm{AlCl}_{3}$ /trimethylamine hydrochloride [39]. With the use of imidazolium based ionic liquids, several works highlight the synthesis of metals (Zn [35], Sn [35,40], Co [41]) and alloys (NiZn [42], CuZn [43], AuZn [44] or FeCoZn [45]) nanowires. Very few works were published concerning Te nanostructures synthesis in RTILs. Al-Salman and co-workers recently [35] synthesized long Te polycrystalline nanowires of several micrometers with diameters between 25 and $35 \mathrm{~nm}$ in the 1-butyl-1-methylpyrrolidinium bis(trifluoromethylsulfonyl)imide ionic liquid containing $\mathrm{SiCl}_{4}$. The authors show in this article that the capping agent is not here the ionic liquid but rather $\mathrm{SiCl}_{4}$ that promotes the growth of Te nanowires. However, the use of $\mathrm{SiCl}_{4}$ leads to the presence of an amorphous and passive layer on the surface of the nanowires, composed of $\mathrm{Si}, \mathrm{C}$ and $\mathrm{O}$, which will alter the electrical properties of these materials.

In a previous work [36], we showed that it is possible to obtain free standing single crystalline Te nanowires at moderate temperature $\left(60-100^{\circ} \mathrm{C}\right)$ in a piperidinium-based ionic liquid mixture: EOPipTFSI:EOPipBr (1-ethyl-1-octylpiperidinium cation, bis(trifluoromethylsulfonyl)imide and bromide anions) without the need of any template. However, the obtained length of the nanowires was limited to $1 \mu \mathrm{m}$ at best, which is not enough for future applications in thermoelectricity. The morphology, size and organization of the structures are very important characteristics that impact physical and chemical properties 
of nanostructured materials. The modulation of these parameters can be achieved by varying electrodeposition conditions in order to obtain one-dimensional nanowires with a high length to diameter aspect ratio for optimal thermoelectric properties. In our previous work, only the influence of electrolyte temperature was investigated. It appeared that the best crystallinity of the deposits was obtained at $100^{\circ} \mathrm{C}$. Here, we present a systematic study of other growth parameters like the applied fixed potential and the composition of the electrolyte on the deposits morphology. The morphology of Te electrodeposits was systematically investigated by scanning electron microscopy (SEM) and transmission electron microscopy (TEM). This work shows that $1 \mathrm{D}$ nanostructures with different morphologies can be obtained resulting from specific mass transport phenomena.

\section{Experimental}

$\mathrm{TeCl}_{4}(99 \%$, Alfa Aesar) was used as Te precursor. EOPipTFSI and EOPipBr were synthesized according to $[46,47]$ and were characterized by nuclear magnetic resonance analysis (Bruker Spectrospin $300 \mathrm{MHz}$ ) and stored in an argon filled glove box (MBraunLabstar; $\mathrm{O}_{2} / \mathrm{H}_{2} \mathrm{O}$ levels $<1 \mathrm{ppm}$ ). A mixture of EOPipTFSI and EOPipBr was used as electrolyte. EOPipBr improves the solubility of $\mathrm{Te}^{\mathrm{IV}}$ salts in TFSI-based ionic liquids probably by the formation of complex halide species [48]. As the viscosity strongly increases with the EOPipBr content [49], the amount of EOPipBr was limited to $5 \%(\mathrm{~mol} / \mathrm{mol})$ that represents the best compromise between a good solubility of the $\mathrm{Te}^{\mathrm{IV}}$ salt and a low electrolyte viscosity.

Electrochemical experiments were performed in a glove box using a Biologic potentiostat (VSP300). Platinum-coated glass slides $(25 \times 10 \times 1 \mathrm{~mm}$, Pt coating thickness $300 \mathrm{~nm}$ with a thin Cr sublayer that ensures a good adherence of the Pt layer), supplied by Applications Couches Minces (ACM), were used both as working and counter electrodes and a Pt wire was used as quasi-reference electrode. The volume of the bath was equal to $5 \mathrm{~mL}$ leading to an 
immerged slide surface of $0.5 \mathrm{~cm}^{2}$. Some specific electroplating synthesis were performed by using a bulk Te anode, which was beforehand prepared by melting Te shots in a square tin at $300^{\circ} \mathrm{C}$. The resulting metallic block was then polished with successively finer grades of SiC Emery paper up to 2400 before use.

The morphology of the deposits was analyzed by SEM (Philips XL30) at $5 \mathrm{kV}$. TEM images of individual nanostructures were recorded by a Philips CM200 transmission electron microscope operating at an accelerating voltage of $200 \mathrm{kV}$. A statistic study from TEM images was carried out on a dozen nanostructures per image to evaluate their mean dimensions (length and diameter) for each experimental condition. The growth direction of the nanostructures was characterized by imaging and selected area electron diffraction (SAED). The diffraction spots were indexed according to the JCPDS card No. 36-1452 of the tellurium hexagonal phase. The crystalline structure of the deposits was investigated by X-ray powder diffraction measurements (XRD, Bruker D8Advance) with $\mathrm{Cu} \mathrm{K}_{\alpha}$ radiation ( $\lambda$ $=1.5406 \AA$ ) at $40 \mathrm{kV}$ and $40 \mathrm{~mA}$.

\section{Results and Discussion}

A typical cathodic linear voltammogram of $\mathrm{Te}^{\mathrm{IV}}$ in the piperidinium-based ionic liquid mixture is presented in Figure 1.

We can observe two reduction peaks at $-0.23 \mathrm{~V}\left(\mathrm{C}_{1}\right)$ and $-1.2 \mathrm{~V}\left(\mathrm{C}_{2}\right)$ vs Pt reference electrode. The electrochemical behavior is the same as observed by Jeng et al. [48] and Tsai et al. [50] in imidazolium based ionic liquids. Consequently, the cathodic peak $\mathrm{C}_{1}$ can be attributed to the reduction of $\mathrm{Te}^{\mathrm{IV}}$ into $\mathrm{Te}^{0}$, this latter being further reduced in $\mathrm{Te}^{-\mathrm{II}}$ at peak $\mathrm{C}_{2}$, according to $[48,50]$. This latter signal represents the cathodic limit for the deposition of $\mathrm{Te}^{0}$ films [36]. It should be noticed that the shape of the cathodic linear voltammograms is the same whatever 
the tellurium salt concentration, exhibiting the $C_{1}$ and $C_{2}$ peaks. However the potential values of the peaks can vary in a $50 \mathrm{mV}$ potential range.

\subsection{Influence of $\mathrm{Te}^{\mathrm{IV}}$ concentration}

The influence of $\mathrm{Te}^{\mathrm{IV}}$ concentration on Te electrodeposition was first studied at $\mathrm{C}_{1}$ peak potential value $\left(\mathrm{E}_{\mathrm{p}}\right)$. Figure 2 presents the SEM images of Te deposits obtained for a coulombic charge of $2 \mathrm{C} \cdot \mathrm{cm}^{-2}$ and $\left[\mathrm{Te}^{\mathrm{IV}}\right]=25 \mathrm{mM}$ (a), $20 \mathrm{mM}$ (b) and $5 \mathrm{mM}$ (c). The results show unambiguously that the increase of the Te precursor concentration has a negative impact on the synthesis of low dimensional structures. For $\left[\mathrm{Te}^{\mathrm{IV}}\right]=25 \mathrm{mM}$ (Figure 2a), corresponding to the maximal solubility of $\mathrm{TeCl}_{4}$ in EOPipTFSI:EOPipBr 95:5 (mol\%), the obtained deposit is dense, composed of nanostructures homogeneous in size of about 150 $\pm 20 \mathrm{~nm}$ in diameter but only $660 \pm 50 \mathrm{~nm}$ in length . For $\left[\mathrm{Te}^{\mathrm{IV}}\right]=20 \mathrm{mM}$ (Figure $2 \mathrm{~b}$ ), a compact deposit is obtained, composed of $1.0 \pm 0.1 \mu \mathrm{m}$ long self-standing nanowires with a mean diameter of $140 \pm 20 \mathrm{~nm}$, homogeneous in size. By decreasing the concentration at 5 $\mathrm{mM}$ (Figure 2c), longer nanowires are obtained, having a mean diameter of $130 \pm 20 \mathrm{~nm}$ and a mean length of $1.2 \pm 0.2 \mu \mathrm{m}$ corresponding to an aspect ratio of $9.2 \pm 3.0$, the longest nanowires reaching $1.8 \pm 0.1 \mu \mathrm{m}$. In these conditions, the nanowires are less homogeneous in size. One can also observe on Figure 2 that for $\left[\mathrm{Te}^{\mathrm{IV}}\right]=5 \mathrm{mM}$, the array of nanowires is less dense than for higher concentration values, suggesting that the density of nuclei is smaller. This is in accordance with the electrocrystallization rules proposed by Scharifker and Hills [51].

SAED analyses were performed and typical diffraction patterns are displayed in the Figure 2, $\mathrm{a}, \mathrm{b}$ and $\mathrm{c}$. All the data exhibit single crystalline phase and the diffraction spots can be indexed to the hexagonal phase of tellurium (JCPDS card No. 36-1452). Whatever the concentration value, the corresponding zone axis is compatible with a growth direction along the $\mathrm{c}$ axis. 
This result is in good agreement with the shapes of nanowires synthesized for $\left[\mathrm{Te}^{\mathrm{IV}}\right]=5 \mathrm{mM}$, exhibiting a well-defined hexagonal shape.

Additional XRD crystallographic analyses of the deposits were performed (see Figure 3). The patterns reveal a preferential orientation along the [001] direction as discussed below.

Except the peaks related to the XRD sample holder and the Pt substrate, all the diffraction peaks can be indexed to the hexagonal phase of tellurium (JCPDS card No. 36-1452), confirming that the deposits are single phase. Sharpness of peaks suggests that the nanowires are well crystallized. In order to obtain a degree of preferential orientation, the Harris' texture coefficient (TC) was systematically calculated according to the following equation:

Equation $2 \mathrm{TC}_{(\mathrm{hkl})}=\frac{\frac{\mathrm{I}_{(\mathrm{hkl})}}{\mathrm{I}_{(0 \mathrm{k})}}}{\frac{1}{\mathrm{~N}} \sum_{\mathrm{I}_{(\mathrm{hkl})}}^{\mathrm{I}_{(\mathrm{hl})}}}$

where $\mathrm{I}_{(\mathrm{hkl})}$ and $\mathrm{I}_{(\mathrm{hkl})}^{0}$ are the measured intensity of a generic peak observed in the experimental XRD and the literature value from the data base (JCPDS card No. 36-1452), respectively, and $\mathrm{N}$ the number of diffraction peaks considered in the analysis. The TC results are presented in Figure 4.

Figure 4 shows that the texture coefficient of the (003) plane is higher than those of other (hkl) planes for $\mathrm{Te}^{\mathrm{IV}}$ concentrations of $20 \mathrm{mM}$ and $25 \mathrm{mM}$. These data corroborate the SEM images (Figure 2a and b), proving that the deposits are composed of dense and [001] oriented nanowires. The [001] orientation is due to the highly anisotropic crystal structure of tellurium(space group P3 121 ). In contrast, no marked orientation is observed for the deposits obtained at $5 \mathrm{mM}$, which can be explained by a random tilt of the nanowires on the substrate (Figure 2c).

\subsection{Influence of applied potential}

The influence of applied potential was studied for two concentration values: $\left[\mathrm{Te}^{\mathrm{IV}}\right]=5 \mathrm{mM}$ (Figure $5 \mathrm{a}-\mathrm{c}$ ), leading to the best aspect ratio at peak potential and $\left[\mathrm{Te}^{\mathrm{IV}}\right]=20 \mathrm{mM}$ (Figure 5 
d-f) for which dense arrays of nanowires were deposited. Three potential zones were tested: the half-wave potential value $\left(\mathrm{E}_{1 / 2}\right)$, corresponding to the potential where the current is half the $C_{1}$ peak current, the $C_{1}$ peak potential value $\left(E_{p}\right)$, and a potential value ( $\left.E_{\text {diff }}\right)$ more negative than $E_{p}\left(E_{\text {diff }}(V)=E_{p}-0.15\right)$. The deposits obtained at peak potential value previously presented in Figure 2 are reminded for easier comparison (Figure 5, b and e).

Whatever the concentration, the deposits obtained at $\mathrm{E}_{1 / 2}$ are compact, composed of faceted micrometric grains (Figure 5, a and d). SAED analysis shows that these structures are single crystalline and grow preferentially along the [001] direction, as previously observed. One can see on Figure 5 that the diameter of the nanostructures decreases with applied overpotential; this phenomenon is more accentuated comparing the $E_{1 / 2}$ deposits and the $E_{p}$ ones. This is in agreement with electrocrystallization principles, that is, the critical size of nuclei is inversely proportional to the deposition overpotential [52].

When the applied potential is much more negative than $\mathrm{C}_{1}$ peak potential (Figure $5, \mathrm{c}$ and $\mathrm{f}$ ), the SEM observations of the deposits show of a compact sublayer composed of small grains and a mix of hollow nanostructures (HNs) and nanowires of several micrometers in length. It has already been shown that, using ionic liquids, HNs can been obtained in specific electrochemical conditions ( $\mathrm{Sn}[40], \mathrm{CuZn}[43]$ and $\mathrm{Cu}_{10} \mathrm{Sn}_{3}[53]$ ).

One can also observe on Figure 5 that the amount of hollow nanostructures increases as the concentration of $\mathrm{Te}^{\mathrm{IV}}$ decreases. This suggests that their formation results from an insufficient species supply. The formation of hollow nanostructures was already observed by Hsieh et al. when studying the synthesis of CuZn nanostructures by template-free electrodeposition [43], but, in their case, the reverse observation was made : HNs were obtained for low overpotential values under charge transfer control, whereas nanowires were obtained at higher overpotential when mass transport is controlling the growth. 
In order to study the formation of HNs, ECD experiments were performed for different coulometric charge values $(\mathrm{Q})$ at low $\mathrm{Te}^{\mathrm{IV}}$ concentration $(5 \mathrm{mM})$ and high overpotential ( $E_{\text {diff }}$, corresponding to the same conditions as Figure 5c. Figure 6 presents the SEM and TEM images of the obtained deposits. As previously, a statistic study from the analysis of 1D nanostructures was carried out to determine their mean dimensions (length and diameter) as a function of Q. Corresponding values and calculated aspect ratio are presented in Figures 7a and $7 \mathrm{~b}$, respectively.

At $100 \mathrm{mC} . \mathrm{cm}^{-2}$ (Figure 6a), the deposit covers the entire working electrode surface and is composed of nanowires. When Q increases up to $200 \mathrm{mC} . \mathrm{cm}^{-2}$ (Figure 6b), some longer 1D nanostructures appear above a sublayer of smaller nanowires. This phenomenon is more and more pronounced as Q increases. One can notice that the nanowires are tip-shaped (inset of Figure 6b) and grow in diameter as fast as in length as shown in Figure 7a. Consequently, the aspect ratio remains constant, $10.0 \pm 1.5$.

The first HNs appear for a coulometric charge of $400 \mathrm{mC} . \mathrm{cm}^{-2}$ (Figure 6c). By still increasing Q, the number of HNs increases (Figure 6, d-f), some of them being hexagonal shaped. Lengths and diameters remain roughly proportional leading thus to the same aspect ratio as previously, $10.0 \pm 1.5$ (Figure $7 \mathrm{a})$.

From the TEM images, it appears then that the nanostructures first grow as nanowires (Figure 6, a and b) and progressively turn into hollow nanostructures (Figure 6, c-f). Consequently, the structures are not hollow from one end to the other (see for example Figure 6, d-e). It seems then that there are several stages of growth: a first stage during which nanowires form, with a center part growing faster than the external parts, leading to tip-shaped structures, as was already observed in literature [34,54]. In the second part of the growth, 1D hollow nanostructures appear. According to Choi's $[55,56]$ works, this formation might be due to a limitation by the diffusion of the precursor ions towards the center part of the growing 
structures. This depletion zone formed in the central part of each structure leads to a faster growth of external parts, resulting in hollow structures formation. The formation of HNs was also observed during hydrothermal synthesis of Te nanostructures by Mayers and Xia [57]. The authors observed the formation of nanotubes when the supply in $\mathrm{Te}^{\mathrm{IV}}$ precursor is ratelimiting whereas nanowires were formed otherwise.

The limitation by species supply seems then to favor the formation of HNs as the coulometric charge increases. To justify this assumption, additional experiments were conducted by using a Te soluble anode as counter electrode in the experimental conditions leading to HNs formation, namely a low tellurium salt concentration $(5 \mathrm{mM})$ and a high overpotential ( $\left.\mathrm{E}_{\mathrm{diff}}\right)$. A typical deposit is presented in Figure 8.

One can observe on Figure 8 that only nanowires are formed. As opposite to the experiments conducted in the same growth conditions without the use of a soluble anode (see Figure 6f), no HNs are noticed. Using a soluble anode, the concentration of $\mathrm{Te}^{\mathrm{IV}}$ in the electrolyte is supposed to be constant during the electrolysis. This hypothesis is based on the presence of the anodic peak corresponding to $\mathrm{Te}(0)$ dissolution, observed by Szymczak et al. in the same electrolyte [49]. Consequently, the diffusion layer thickness remains constant during the whole experiments leading to constant diffusion flux.

Obtained nanowires are not very homogeneous in size and their density is low. However, the mean length is $5.0 \pm 2.0 \mu \mathrm{m}$ whereas without the use of a soluble anode, it is of $2.7 \pm 1.0 \mu \mathrm{m}$. The mean diameter remains the same that previously observed, $250 \pm 100 \mathrm{~nm}$. The use of a soluble anode allows then to obtain NWs instead of HNs, with larger length and equivalent diameter. Thus this additional result confirms that the growth of HNs is related to species supply.

The conducted experiments in this work show that the origin of the nanostructuration (NWs and HNs) is governed by the applied overpotential and the cationic concentration. It should be 
noted that, from the literature data [36-45], ionic liquids could play the role of capping agents. Besides, halide anions can also be responsible of the growth of nanostructures as observed by Al-Salman et al. [35]. In our work, it is difficult to discriminate between halide effect and IL ions effect, as the only Te(IV) salts that are soluble in TFSI-based ionic liquids are halide salts.

\section{Conclusions}

In this work, we have shown that it is possible to control the shape and the size of the deposited nanostructures by varying the experimental parameters that influence the deposition kinetics. It appears in particular that the applied potential has a very strong influence on the deposit morphology. Under charge transfer control, micrometer faceted grains are observed. Under diffusional control, the deposits are composed of nanowires. In high overpotential conditions, nanowires turn progressively into hollow nanostructures due to a limitation by species supply. This phenomenon is more accentuated at low concentration.

This work shows that Te nanowires of high crystallinity can be obtained by electrodeposition in ionic liquids. They could be used as starting materials for the synthesis of core-shell structures. Hollow nanostructures synthesized in specific conditions are also interesting to create high performances thermoelectric materials. Indeed, this geometry could further decrease the lattice part of the thermal diffusion coefficient by phonon confinement. 


\section{References}

[1] T.I. Lee, S. Lee, E. Lee, S. Sohn, Y. Lee, S. Lee, G. Moon, D. Kim, Y.S. Kim, J.M. Myoung, Z.L. Wang, High-power density piezoelectric energy harvesting using radially strained ultrathin trigonal tellurium nanowires assembly, Adv. Mater. 25 (2013) 2920.

[2] D.Tsiulyanu, O. Mocreac, Concentration induced damping of gas sensitivity in ultrathin tellurium films, Sensors and Actuators B 177 (2013) 1128.

[3] H.H. Li, P. Zhang, C.L. Liang, J. Yang, M. Zhou, X.H. Lu, G.A. Hope, Facile electrochemical synthesis of tellurium nanorods and their photoconductive properties, Cryst. Res. Technol. 47 (2012) 1069.

[4] S. Ito, N. Kitagawa, T. Shibahara, H. Nishino, Electrochemical deposition of Te and Se on flat $\mathrm{TiO}_{2}$ for solar cell application, International Journal of Photoenergy (2014).

[5] B. Abad, M. Rull-Bravo, S. Hodson, X. XU, M.S. Martín-González, Thermoelectric properties of electrodeposited tellurium films and the sodium lignosulfonate effect, Electrochimica Acta 169 (2015) 43.

[6] M.S. Martín-González, O. Caballero-Calero, P. Díaz-Chao, Nanoengineering thermoelectric for $21^{\text {st }}$ century: Energy harvesting and other trends in the field, Renewable and Sustainable Energy Reviews 24 (2013) 288-305.

[7] D.A. Borca-Tasciuc, G. Chen, A. Prieto, M.S. Martín-González, A. Stacy, T. Sands, M.A. Ryan, J.P. Fleurial, Thermal properties of electrodeposited bismuth telluride nanowires embedded in amorphous alumina, Appl. Phys. Lett. 85 (2004) 6002.

[8] M.S. Dresselhaus, G. Chen, M.Y. Tang, R. Yang, H. Lee, D. Wang, Z. Ren, J-P. Fleurial, P. Gogna, New directions for low-dimensional thermoelectric materials, Adv. Mater. 19 (2007) 1045.

[9] M.G. Kanatzidis, Nanostructured thermoelectrics: The new paradigm ?, Chem. Mater. $22(2010) 648$. 
[10] O. Caballero-Calero, M.S. Martín-González, Thermoelectric nanowires: A brief prospective, Scripta Materialia (2015), in press, doi:10.1016/j.scriptamat.2015.04.020. [11] J. Kim , J-H. Bahk, J. Hwang, H. Kim, H. Park, W. Kim, Thermoelectricity in semiconductor nanowires, Phys. Status Solidi 10 (2013) 769.

[12] R. Yang, G. Chen, M.S. Dresselhaus, Thermal conductivity of simple and tubular nanowires composites in the longitudinal direction, Physical review B 72 (2005) 125418-5.

[13] G. Zhang, Q. Yu, W. Wang, X. Li, Nanostructures for thermoelectric applications: synthesis, growth mechanism, and properties studies, Adv. Mater. 22 (2010) 1959.

[14] R. Yang, G. Chen, M.S. Dresselhaus, Thermal conductivity modeling of core-shell and tubular nanowires, Nano Lett. 5 (2005) 1114.

[15] S.J. Poon, A.S. Petersen, D. Wu, Thermal conductivity of core-shell nanocomposites for enhancing thermoelectric performance, Appl. Phys. Lett. 102 (2013) 173110-3.

[16] Y. Yang, C. Gao, J. li, The effective thermoelectric properties of core-shell composites, Acta Mech. 225 (2014) 1220.

[17] J. Kang, J.W. Roh, W. Shim, J. Ham, J-S. Noh, W. Lee, Reduction of lattice thermal conductivity in single Bi-Te core/shell nanowires with rough interface, Adv. Mater. 23 (2011) 3417.

[18] G. Zhang, W. Wang, X. Li, Enhanced thermoelectric properties of core/shell heterostructure nanowires composites, Adv. Mater.20 (2008) 3654.

[19] J. Zhou, C. Jin, J.H. Seol, X. Li, L. Shi, Thermoelectric properties of individual electrodeposited bismuth telluride nanowires, Appl. Phys. Lett. 87 (2005) 133109-2.

[20] H. Fang, H. Yang, Y. Wu, Thermoelectric properties of silver telluride-bismuth telluride nanowire heterostructure synthesized by site-selective conversion, Chem. Mater. 26 (2014) 3325 . 
[21] P. Gnanadurai, N. Soundararajan, C.E. Sooriamoorthy, Investigation on the influence of thickness and temperature on the Seebeck coefficient of silver telluride thin films, Vacuum 67 (2002) 278.

[22] H. Yang, J-H.Bahk, T. Day, A.M.S. Mohammed, G.J. Snyder, A. Shakouri, Y. Wu, Enhanced thermoelectric properties in bulk nanowires heterostructure-based nanocomposites through minority carrier blocking, Nano Lett. 15 (2015) 1353.

[23] A.F. May, J-P. Fleurial, G.J Snyder, Thermoelectric performance of lanthanum telluride produced via mechanical alloying, Physical Review B 78 (2008) 125205-10.

[24] C.J. Hawley, B.R. Beatty, G. Chen, J.E. Spanier, Shape-controlled vapor-transport growth of tellurium nanowires, Cryst.Growth Des. 12 (2012) 2789.

[25] P. Mohanty, J. Park, B. Kim, Large scale synthesis of highly pure single crystalline tellurium nanowires by thermal evaporation method, J. Nanosci. Nanotechnol. 6 (2006) 3381 . [26] H. Park, W. Son, S.H. Lee, S. Kim, J.J. Lee, W. Cho, H.H. Choi, J.H. Kim, Aqueous chemical synthesis of tellurium nanowires using a polymeric template for thermoelectric materials, Cryst. Eng. Comm. 17 (2015) 1093.

[27] Z. Liu, S. Li, Y. Yang, Z. Hu, S. Peng, J. Liang, Y. Qian, Shape-controlled synthesis and growth mechanism of one-dimensional nanostructures of trigonal tellurium, New $\mathbf{J}$. Chem. 27 (2003) 1749.

[28] F. Liang, H. Qian, Synthesis of tellurium nanowires and their transport property, Mater. Chem. Phys. 113 (2009) 523.

[29] T. Wu, L.Y. Myung, M. Zhang, K.H. Lee, Y.L. Lee, H.R. Lim, B.S. Kim, Y.H. Choa, N.V. Myung, Size controlled synthesis of Tellurium nanorices by galvanic displacement reaction of aluminium, Electrochim. Acta 176 (2015) 1385. 
[30] D. Elazem, H. Jung, T. Wu, J-H. Lim, K-H. Lee, N.V. Myung, Morphology change of galvanically displaced one-dimensional tellurium nanostructures via controlling the microstructure of sacrificial Ni thin films, Electrochim. Acta 106 (2013) 448.

[31] D-B. Jeong, J-H. Lim, J. Lee, H. Park, M. Zhang, Y-I. Lee, Y-H. Choa, N.V. Myung, Template-free synthesis of vertically oriented tellurium nanowires via a galvanic displacement reaction, Electrochim. Acta 111 (2013) 201.

[32] G. She, W. Shi, X. Zhang, T. Wong, Y. Cai, N. Wang, Template-free electrodeposition of one-dimensional nanostructures of tellurium, Cryst. Growth Des. 9 (2009) 664.

[33] A. Zhao, L. Zhang, Y. Pang, C. Ye, Ordered tellurium nanowire arrays and their optical properties, Appl. Phys. A 80 (2005) 1725.

[34] N. Kumar, R. Kumar, S. Kumar, S.K. Chakarvarti, Optical and electrical studies of vertically oriented tellurium nanowires arrays produced by template electrodeposition, J. of Electron. Mater. (2015).

[35] R. Al-Salman, H. Sommer, T. Brezesinski, J. Janek, Template-free electrochemical synthesis of high aspect ratio Sn nanowires in ionic liquids: A general route to large-area metal and semimetal nanowires arrays?, Chem. Mater. 27 (2015) 3831.

[36] J. Szymczak, S. Legeai, S. Diliberto, S. Migot, N. Stein, C. Boulanger, G. Chatel, M. Draye, Template-free electrodeposition of tellurium nanostructures in a room-temperature ionic liquid, Electrochem. Comm. 24 (2012) 57.

[37] J. Ma, J. Lian, X. Duan, Z. Liu, P. Peng, X. Liu, T. Kim, W. Zheng, Growth of tellurium nanowire bundles from an ionic liquid precursor, Cryst. Eng. Comm. 13 (2011) 2775 .

[38] M. Steichen, P. Dale, Synthesis of trigonal selenium nanorods by electrodeposition from an ionic liquid at high temperature, Electrochem. Comm. 13 (2011) 865. 
[39] C-J. Su, Y-T.Hsieh, C-C.Chen, I-W. Sun, Electrodeposition of aluminium wires from the Lewis acidic $\mathrm{AlCl}_{3}$ /trimethylamine hydrochloride ionic liquid without using a template, Electrochem. Comm. 34 (2013) 171.

[40] T-I. Leong, Y-T.Hsieh, I-W.Sun, Electrochemistry on tin in the 1-ethyl-3methylimidazolium dicyanamide room temperature ionic liquid, Electrochim. Acta 56 (2011) 3942.

[41] Y-T. Hsieh, M-C.Lai, H-L.Huang, I-W. Sun, Speciation of cobalt-chloride-based ionic liquids and electrodeposition of Co wires, Electrochim. Acta 117 (2014) 218.

[42] J-M. Yang, S-P.Gou, I-W. Sun, Single-step large-scale and template-free electrochemical growth of Ni-Zn alloy filament arrays from a zinc chloride based ionic liquid, Chem. Commun. 46 (2010) 2687.

[43] Y-T. Hsieh, R-W. Tsai, C-J. Su, I-W. Sun, Electrodeposition of CuZn from chlorozincate ionic liquid : from hollow tubes to segmented nanowires, J. Phys. Chem. 118 (2014) 22348

[44] Y-T. Hsieh, I-W. Sun, One-step electrochemical fabrication of nanoporous gold wire arrays from ionic liquid, Chem. Commun. 50 (2014) 246.

[45] J-M. Yang, Y-T. Hsieh, D-X. Zhuang, I-W. Sun, Direct electrodeposition of FeCoZn wire arrays from a zinc chloride-based ionic liquid, Electrochem. Comm. 13 (2011) 1178.

[46] A. Triolo, O. Russina, B. Fazio, G.B. Appetecchi, M. Carewska, S. Passerini, Nanoscale organization in piperidinium-based room temperature ionic liquids, J. Chem. Phys. 130 (2009) 164521-1.

[47] Y. Traore, S. Legeai, S. Diliberto, G. Arrachart, S. Pellet-Rostaing, M. Draye, New insight into indium electrochemistry in a $\mathrm{Tf}_{2} \mathrm{~N}$-based room-temperature ionic liquid, Electrochim. Acta 58 (2011) 533. 
[48] E.G-S. Jeng, I-W. Sun, Electrochemistry of tellurium(IV) in the basic aluminium chloride-1-methyl-3-ethylimidazolium chloride room temperature molten salts, J. Electrochem. Soc. 144 (1997) 2369.

[49] J. Szymczak, S. Legeai, S. Michel, S. Diliberto, N. Stein, C. Boulanger, Electrodeposition of stoichiometric bismuth telluride $\mathrm{Bi}_{2} \mathrm{Te}_{3}$ using a piperidinium ionic liquid binary mixture, Electrochim. Acta 137 (2014) 587.

[50] R.W. Tsai, Y.T. Hsieh, P.Y. Chen, I.W. Sun, Voltammetric study and electrodeposition of tellurium, lead, and lead telluride in room-temperature ionic liquid 1ethyl-3-methylimidazolium tetrafluoroborate, Electrochim. Acta 137 (2014) 50. [51] B. [51] Scharifker, G. Hills, Theoretical and experimental studies of multiple nucleation, Electrochim. Acta 28 (1983) 880.

[52] M. Paunovic, M. Schlesinger, Fundamentals of electrochemical deposition, Ch. 7, John Wiley \& Sons, Inc., United States of America, 2006, p.114.

[53] Y-T. Hsieh, T-I. Leong, C-C. Huang, C-S. Yeh, I-W. Sun, Direct template-free electrochemical growth of hexagonal $\mathrm{CuSn}$ tubes from an ionic liquid, Chem. Commun. 46 (2010) 485 .

[54] X. Guo, T. Zhang, J. Li, T. Fan, Butterfly-scale architecture directed electrodeposition of Ag microband arrays for electrochemical detection, RSC Adv. 4 (2014) 59510

[55] M.J. Siegfried, K-S. Choi, Directing the architecture of cuprous oxide crystals during electrochemical growth, Angew. Chem. Int. Ed. 44 (2005) 3219.

[56] K-S. Choi, Shape control of inorganic materials via electrodeposition, Dalton Trans. (2008) 5434.

[57] B. Mayers, Y. Xia, Formation of tellurium nanotubes through concentration depletion at the surfaces of seeds, Adv. Mater. 14 (2002) 281. 


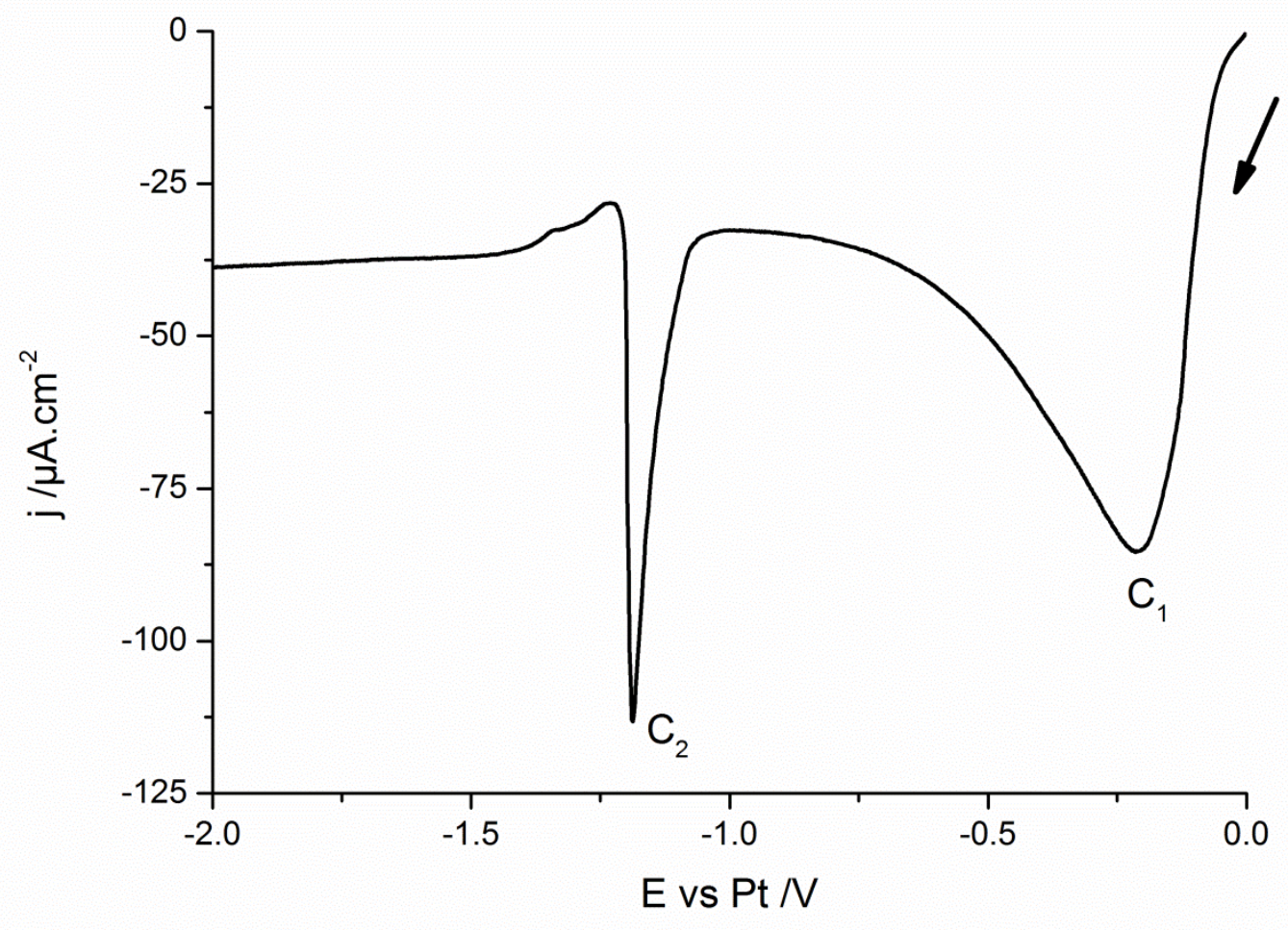

Figure 1: Cathodic behaviour of $\mathrm{Te}^{\mathrm{IV}}$ in EOPipTFSI:EOPipBr 95:5 (mol\%). $\left[\mathrm{TeCl}_{4}\right]=20 \mathrm{mM}$. Pt-coated glass slide substrate. $\mathrm{T}=100^{\circ} \mathrm{C}$, scan rate $5 \mathrm{mV} \cdot \mathrm{s}^{-1}$. 


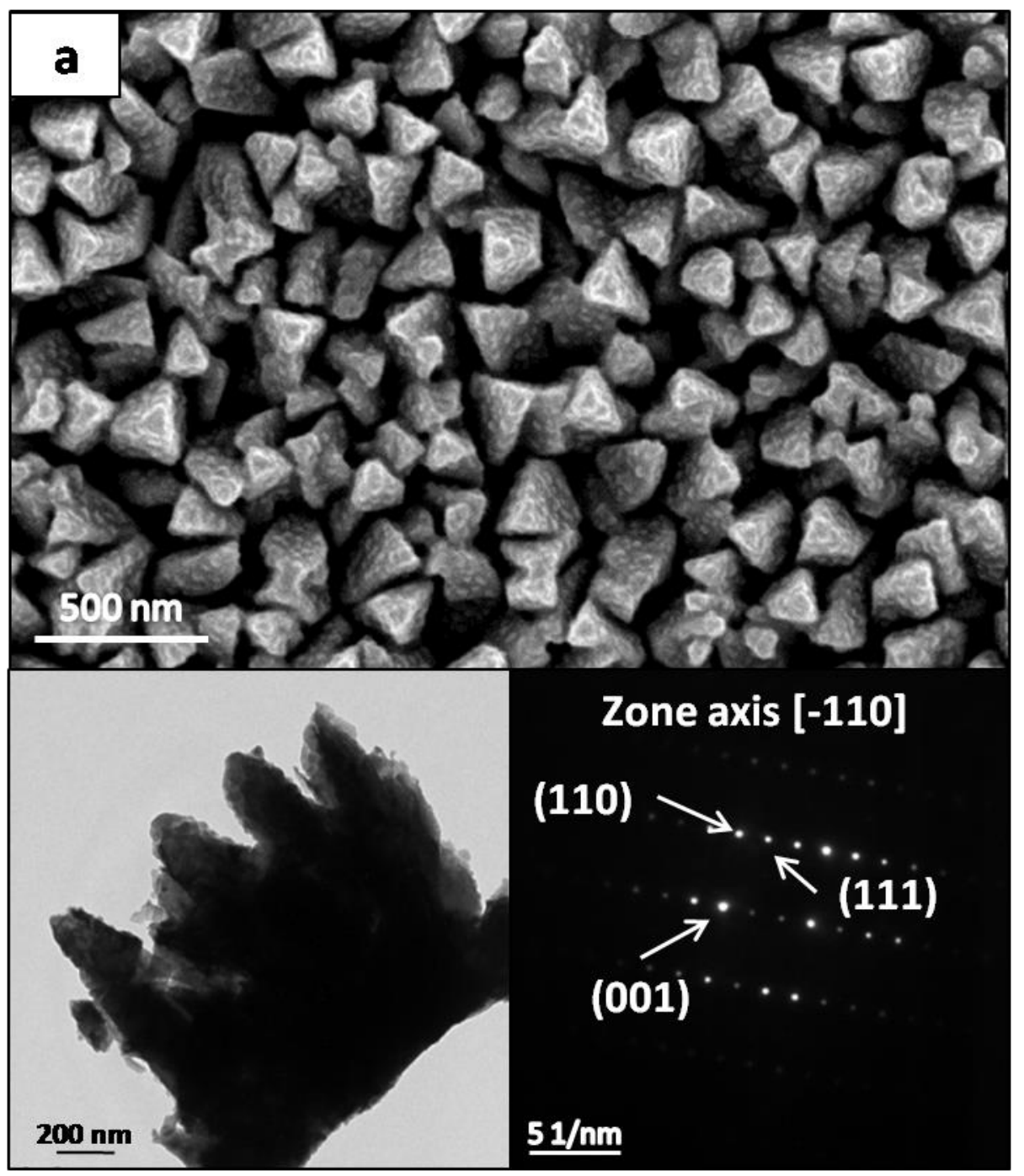




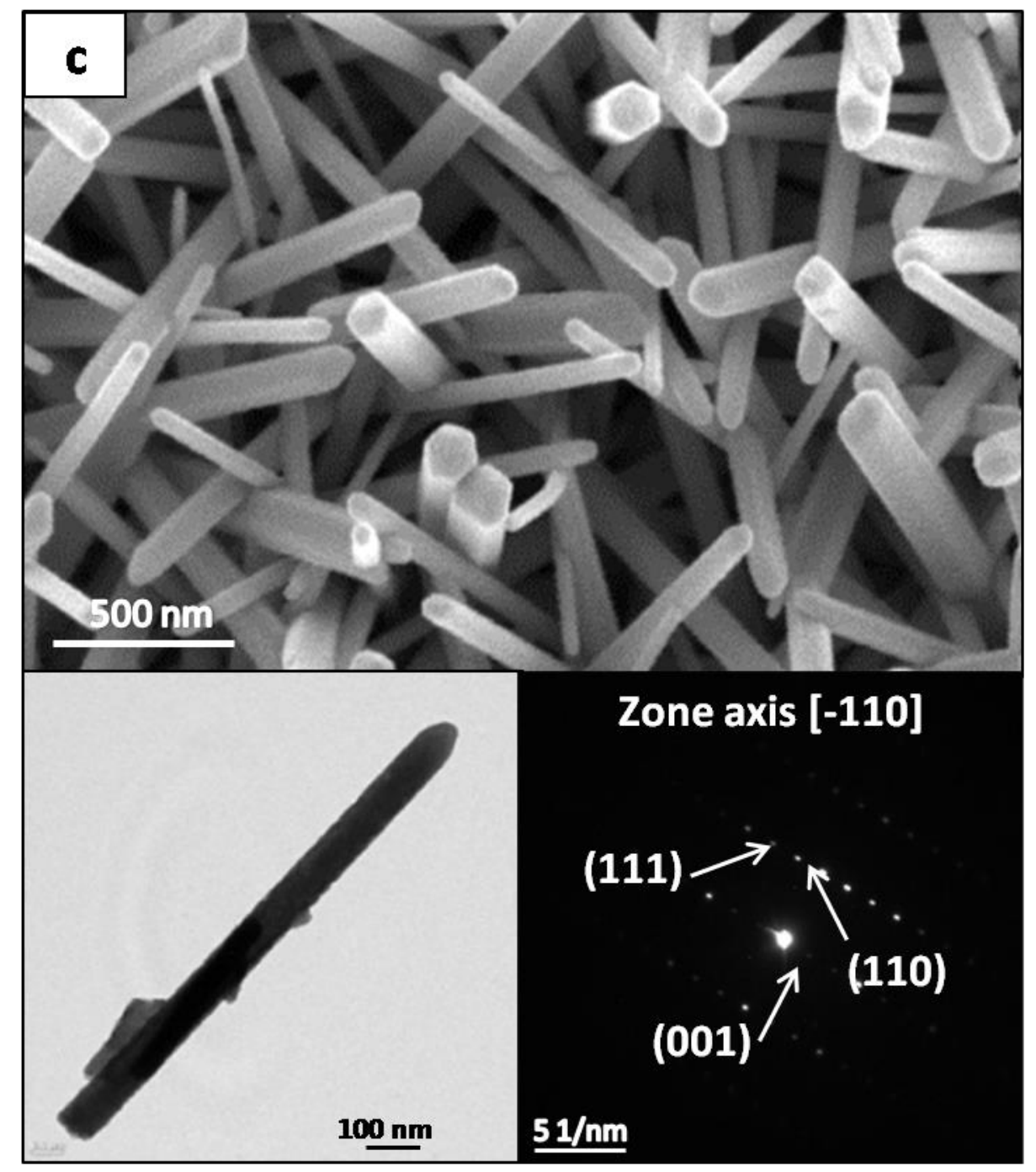

Figure 2: SEM images of Te nanostructures electrodeposited at $\mathrm{E}_{\mathrm{dep}}=\mathrm{E}_{\mathrm{p}}$ in

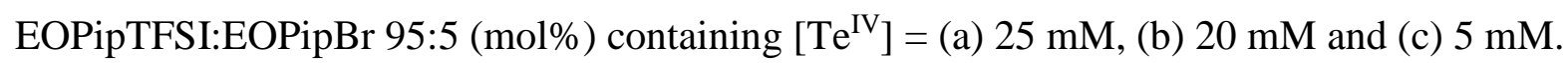
$\mathrm{T}=100^{\circ} \mathrm{C}, \mathrm{Q}=2 \mathrm{C} . \mathrm{cm}^{-2}, \mathrm{Pt}-$ coated glass slide, $0.5 \mathrm{~cm}^{2}$. Insets show corresponding TEM images and SAED diffractograms (the diffraction spots are indexed to the tellurium phase CPDS card No. 36-1452). 


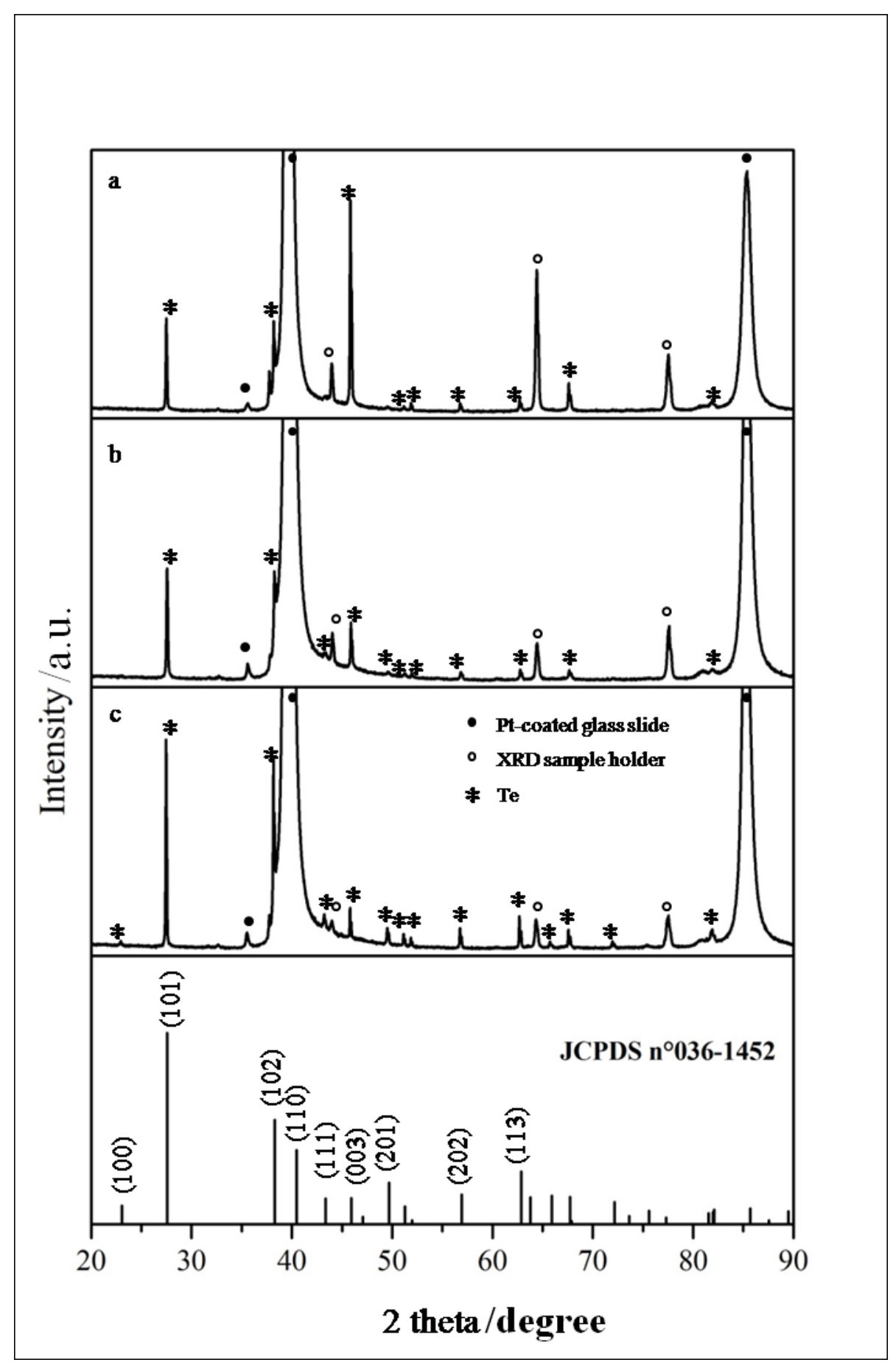

Figure 3: XRD pattern of a Te deposit

Pt-coated glass slide, $\left[\mathrm{Te}^{\mathrm{IV}}\right]=$ (a) $25 \mathrm{mM}$, (b) $20 \mathrm{mM}$ and (c) $5 \mathrm{mM}$. 


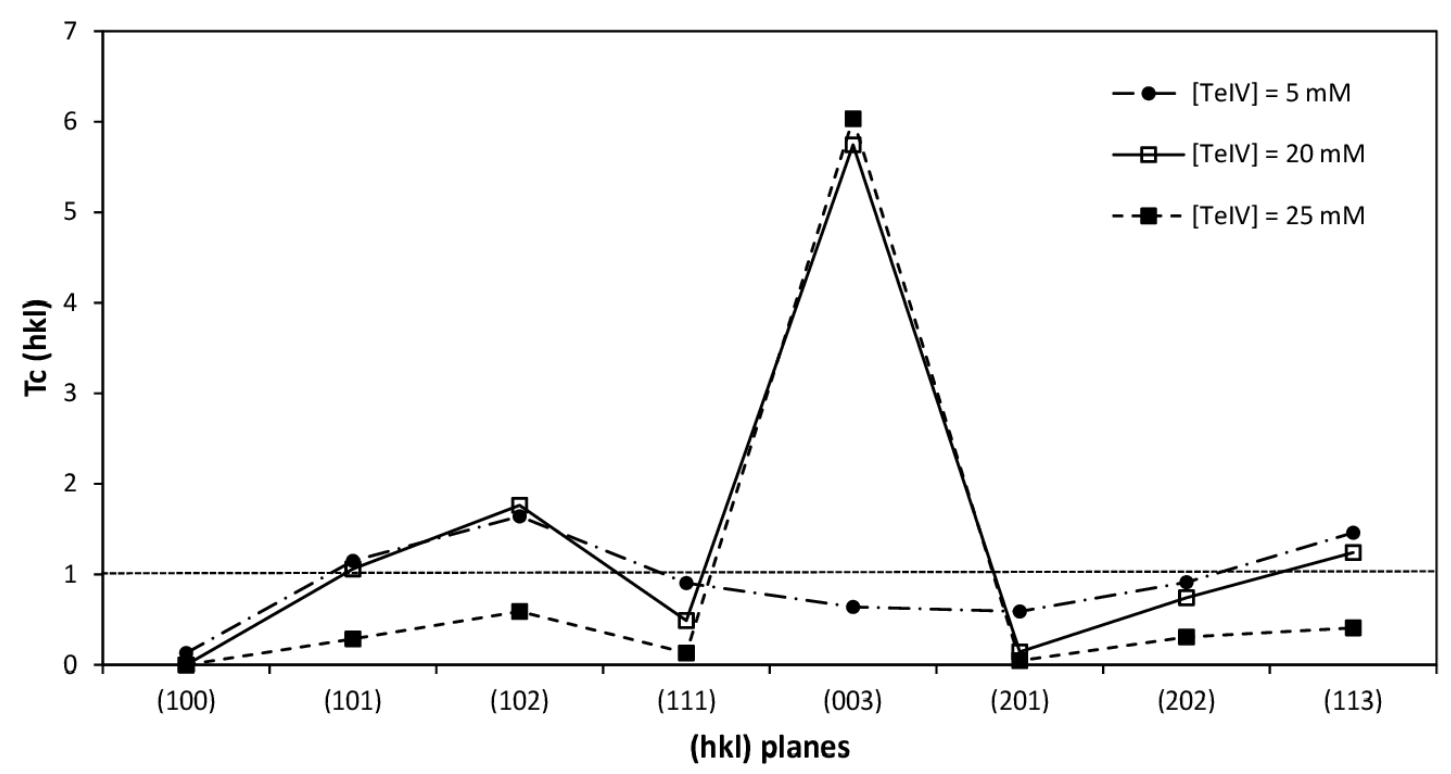

Figure 4: Texture coefficients of tellurium nanowires according to (hkl) planes, calculated from XRD data presented in Figure 3 

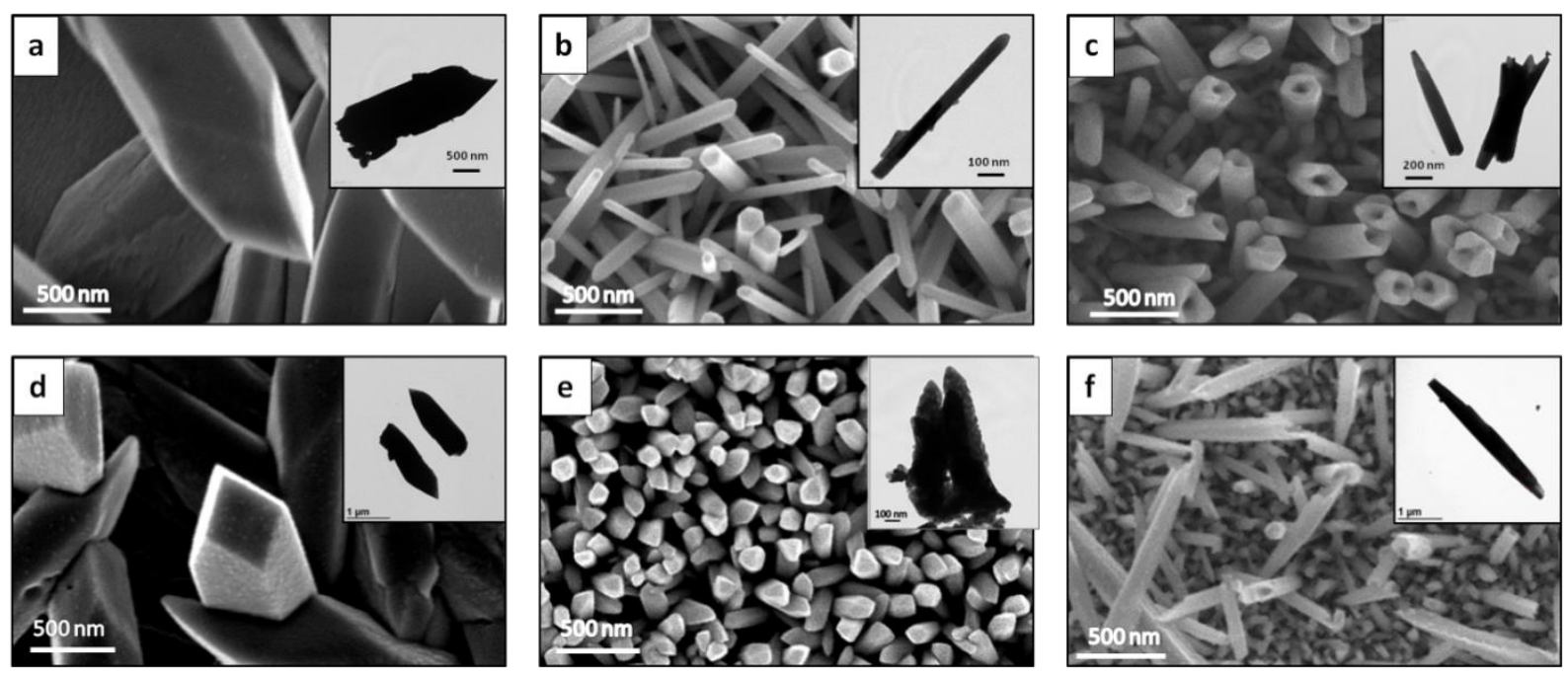

Figure 5: SEM images of Te nanostructures deposited in EOPipTFSI:EOPipBr 95:5 (mol\%) for different applied potential values. $\mathrm{T}=100^{\circ} \mathrm{C}, \mathrm{Q}=2 \mathrm{C} \cdot \mathrm{cm}^{-2}$, Pt-coated glass slide. Insets show the TEM images.

$\left[\mathrm{Te}^{\mathrm{IV}}\right]=5 \mathrm{mM}$ : (a) $\mathrm{E}_{1 / 2}$, (b) $\mathrm{E}_{\mathrm{p}}$ and (c) $\mathrm{E}_{\mathrm{diff}} ;\left[\mathrm{Te}^{\mathrm{IV}}\right]=20 \mathrm{mM}$ : (d) $\mathrm{E}_{1 / 2}$, (e) $\mathrm{E}_{\mathrm{p}}$ and (f) $\mathrm{E}_{\mathrm{diff}}$ 

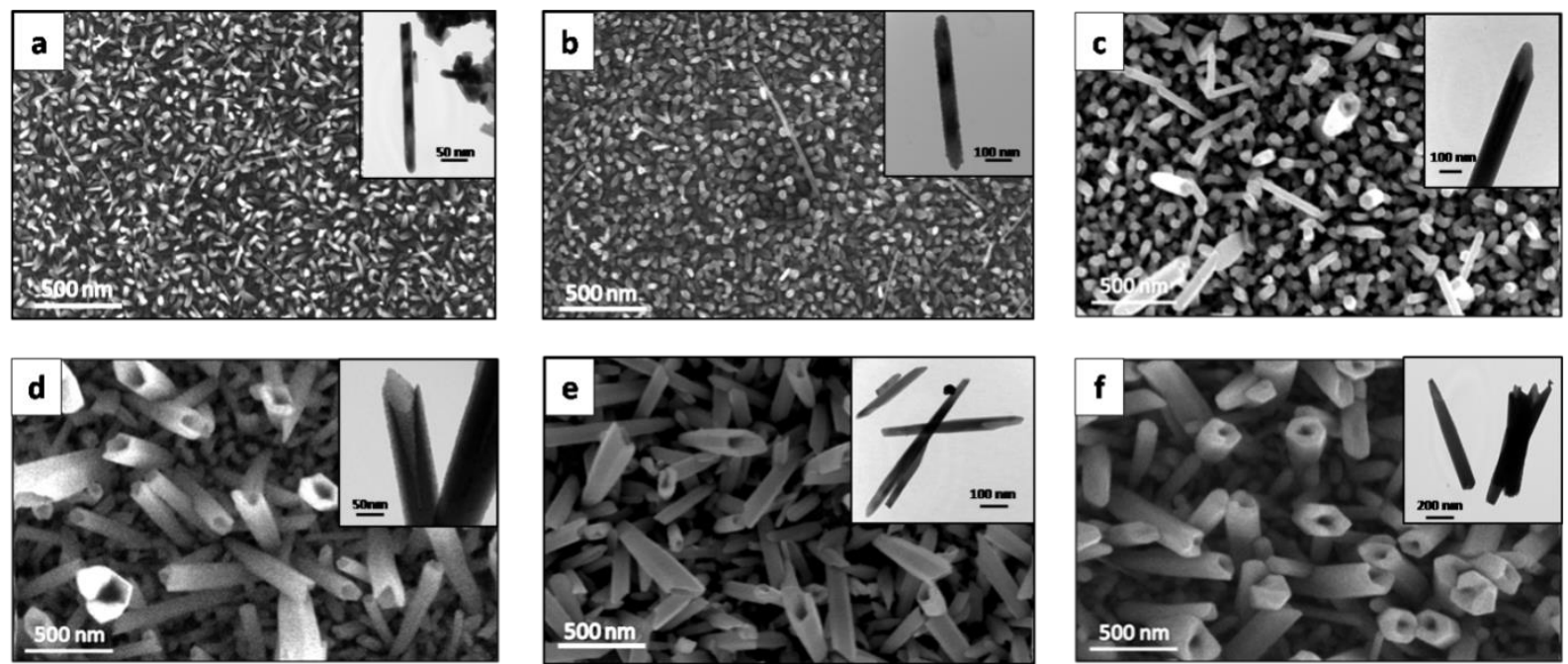

Figure 6: SEM images of Te nanostructures electrodeposited for different coulometric charge values in EOPipTFSI:EOPipBr 95:5 (mol\%), $\mathrm{E}_{\mathrm{dep}}=\mathrm{E}_{\mathrm{diff}},\left[\mathrm{Te}^{\mathrm{IV}}\right]=5 \mathrm{mM}$,
(a) $100 \mathrm{mC} . \mathrm{cm}^{-2}$,
(b) $200 \mathrm{mC} . \mathrm{cm}^{-2}$,
(c) $400 \mathrm{mC} . \mathrm{cm}^{-2}$,
(d) $800 \mathrm{mC} . \mathrm{cm}^{-2}$,
(e) 1 C.cm ${ }^{-2}$ and (f) 2
C. $\mathrm{cm}^{-2}, \mathrm{~T}=100^{\circ} \mathrm{C}$, Pt-coated glass slide

Insets show the TEM images of Te nanostructures. 
a)

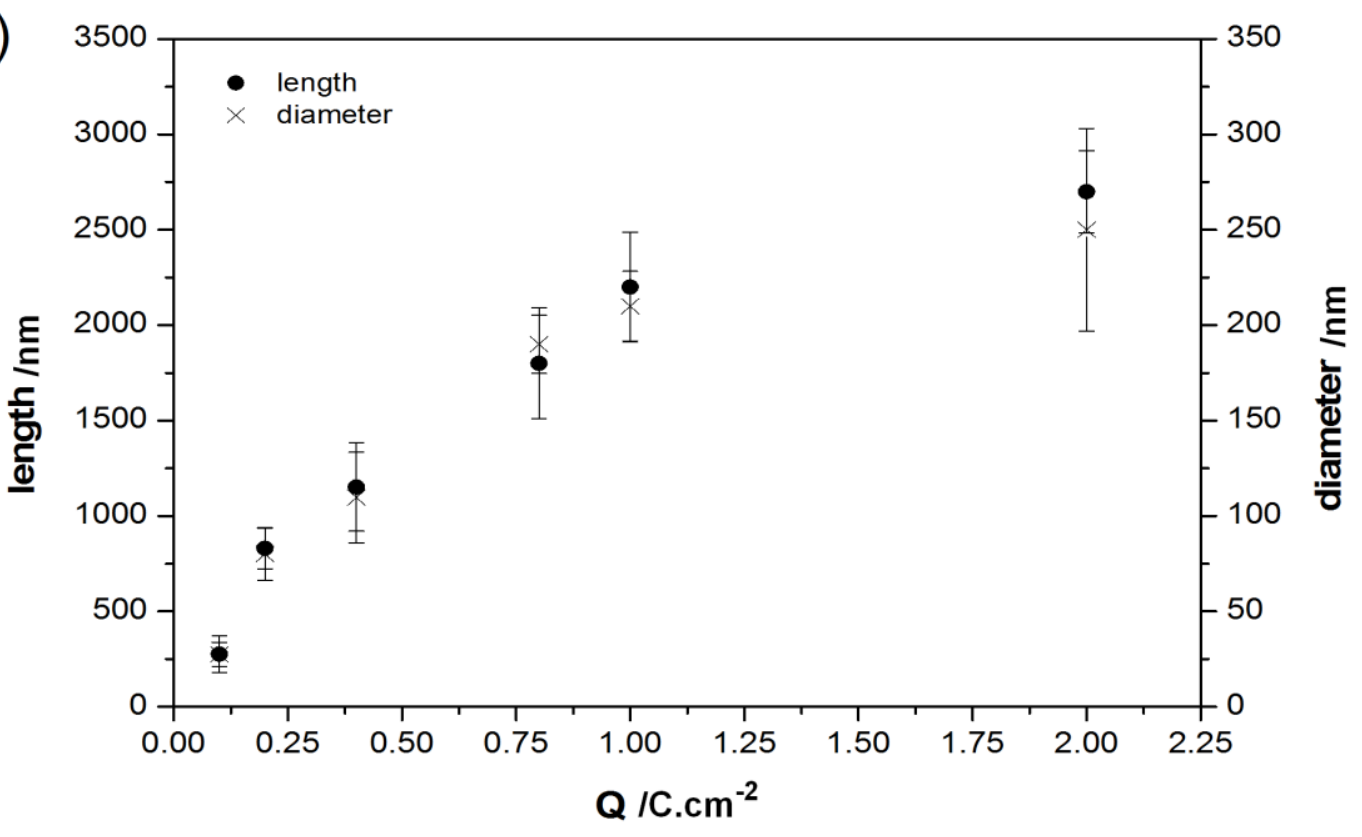

b)

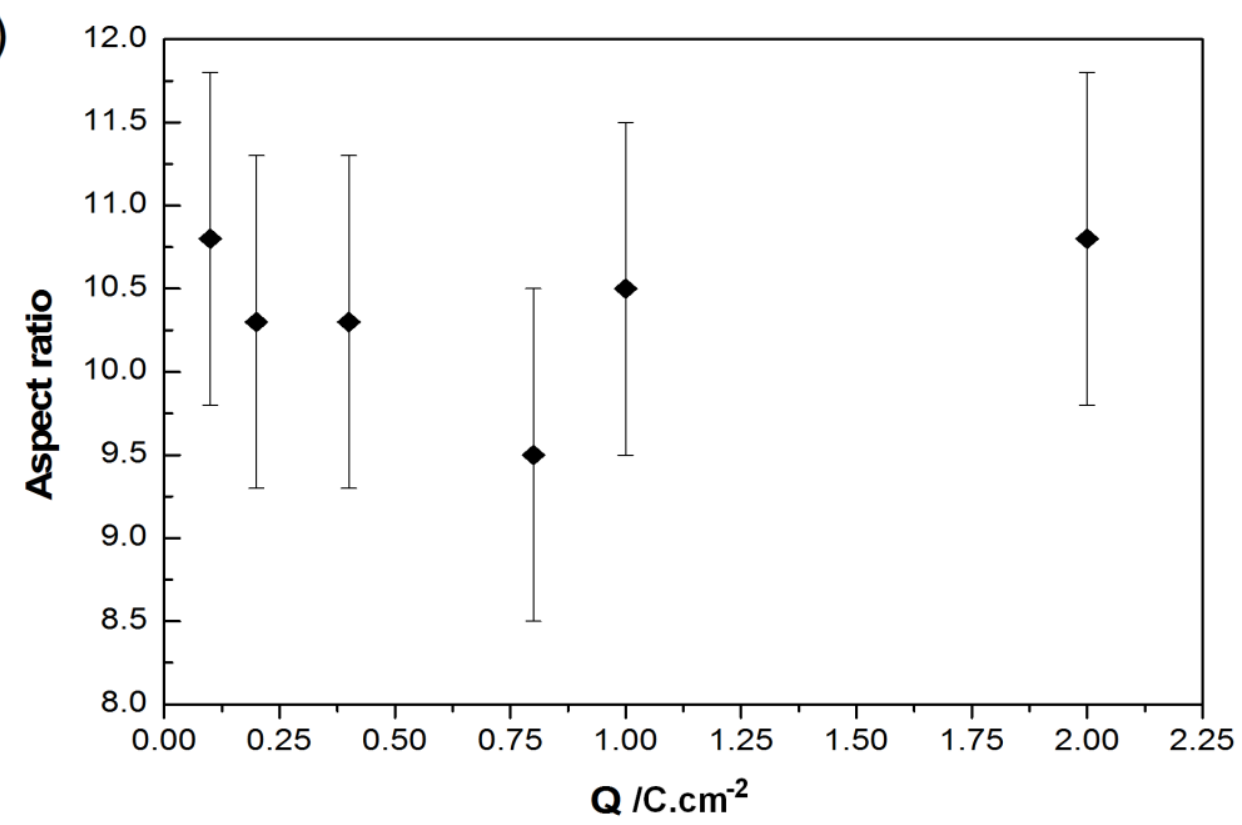

Figure 7: Evolution of a) length and diameter and b) aspect ratio of Te one-dimensional 
nanostructures according to applied coulometric charge value, $\left[\mathrm{Te}^{\mathrm{IV}}\right]=5 \mathrm{mM}, \mathrm{E}_{\mathrm{dep}}=\mathrm{E}_{\text {diff }}$

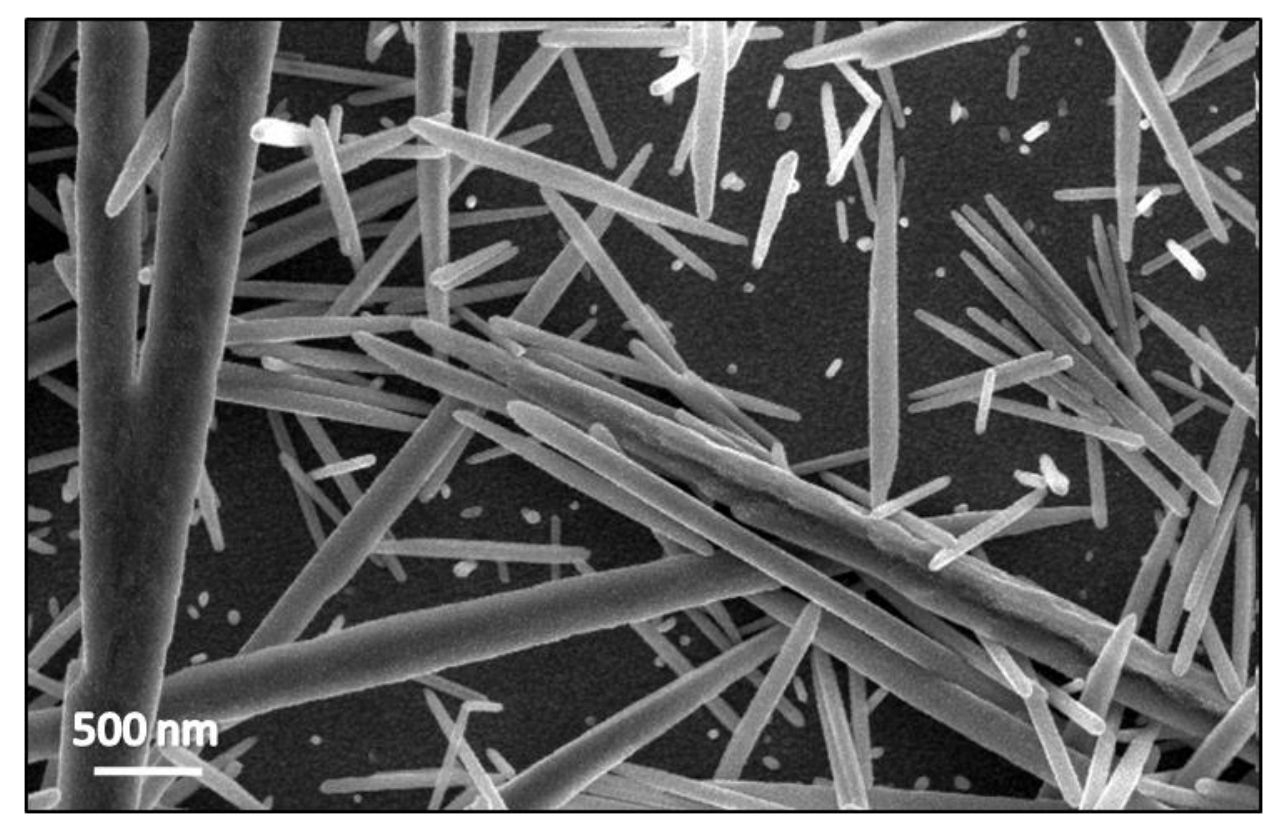

Figure 8: SEM images of Te nanostructures electrodeposited with a Te soluble anode in

EOPipTFSI:EOPipBr 95:5 (mol\%), $\mathrm{E}_{\text {dep }}=\mathrm{E}_{\mathrm{diff}},\left[\mathrm{Te}^{\mathrm{IV}}\right]=5 \mathrm{mM}, \mathrm{T}=100^{\circ} \mathrm{C}, \mathrm{Q}=2 \mathrm{C} . \mathrm{cm}^{-2}, \mathrm{Pt}-$ coated glass slide. 